BMC

Public Health

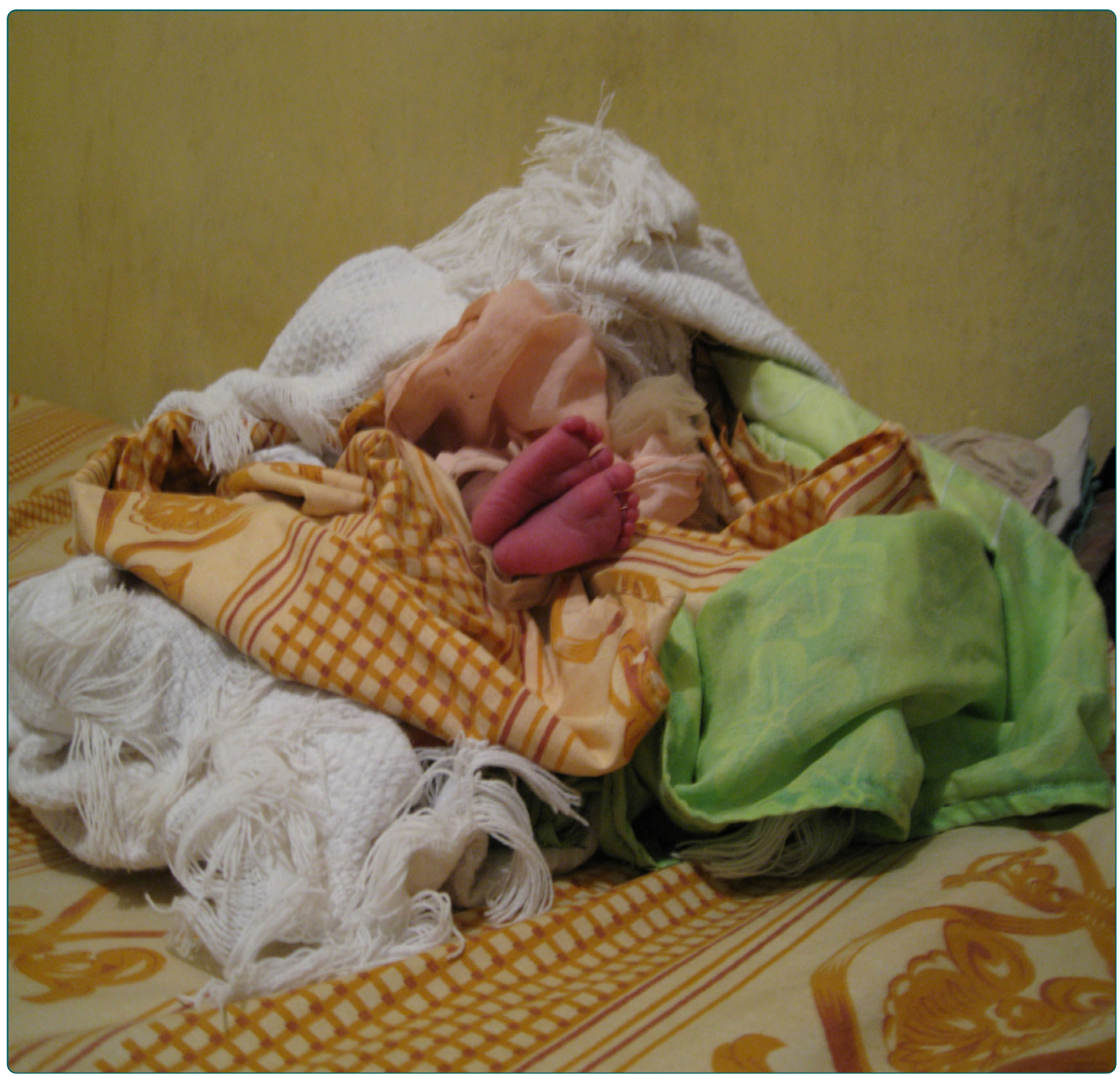

Measuring newborn foot length to identify small babies in need of extra care: a cross sectional hospital based study with community follow-up in Tanzania

Marchant et al. 


\title{
Measuring newborn foot length to identify small babies in need of extra care: a cross sectional hospital based study with community follow-up in Tanzania
}

Tanya Marchant $^{1 *}$, Jennie Jaribu ${ }^{2}$, Suzanne Penfold ${ }^{2,3}$, Marcel Tanner $^{4}$, Joanna Armstrong Schellenberg ${ }^{3}$

\begin{abstract}
Background: Neonatal mortality because of low birth weight or prematurity remains high in many developing country settings. This research aimed to estimate the sensitivity and specificity, and the positive and negative predictive values of newborn foot length to identify babies who are low birth weight or premature and in need of extra care in a rural African setting.

Methods: A cross-sectional study of newborn babies in hospital, with community follow-up on the fifth day of life, was carried out between 13 July and 16 October 2009 in southern Tanzania. Foot length, birth weight and gestational age were estimated on the first day and foot length remeasured on the fifth day of life.

Results: In hospital 529 babies were recruited and measured within 24 hours of birth, 183 of whom were also followed-up at home on the fifth day. Day one foot length $<7 \mathrm{~cm}$ at birth was $75 \%$ sensitive $(95 \% \mathrm{Cl} 36-100)$ and $99 \%$ specific (95\%Cl 97-99) to identify very small babies (birth weight $<1500$ grams); foot length $<8 \mathrm{~cm}$ had sensitivity and specificity of $87 \%(95 \% \mathrm{Cl} 79-94)$ and $60 \%(95 \% \mathrm{Cl} 55-64)$ to identify those with low birth weight ( $<2500$ grams), and $93 \%(95 \% \mathrm{Cl} 82-99)$ and $58 \%(95 \% \mathrm{Cl} 53-62)$ to identify those born premature ( $<37$ weeks). Mean foot length on the first day was $7.8 \mathrm{~cm}$ (standard deviation 0.47); the mean difference between first and fifth day foot lengths was $0.1 \mathrm{~cm}$ (standard deviation 0.3): foot length measured on or before the fifth day of life identified more than three-quarters of babies who were born low birth weight.

Conclusion: Measurement of newborn foot length for home births in resource poor settings has the potential to be used by birth attendants, community volunteers or parents as a screening tool to identify low birth weight or premature newborns in order that they can receive targeted interventions for improved survival
\end{abstract}

\section{Background}

Despite important gains in the survival of children under five years in sub-Saharan Africa during the last twenty years, the neonatal mortality rate (NMR) remains virtually unchanged at 41 deaths within 28 days of birth for every 1000 live births. This currently represents an estimated $41 \%$ of all under five deaths [1].

The majority of these deaths occur in settings where the health system is weak and robust data is scarce. However, a recent focus on the topic has lead to some

\footnotetext{
* Correspondence: tanya.marchant@Ishtm.ac.uk

'Department of Global Health and Development, LSHTM, 15-17 Tavistock Place, London WC1H 9SH, UK
}

consensus about causes and actions to be taken. The three main causes of neonatal death are intra-partum related, complications due to prematurity or low birth weight, and infection [1,2]. As many as three-quarters of deaths occur in the first week of life, and up to $90 \%$ of all babies who die are born low birth weight (LBW $<2500$ grams) either because of prematurity or intrauterine growth restriction [2]. Community level interventions including skin-to-skin contact (also known as Kangaroo Mother Care), immediate and frequent breastfeeding, and active care seeking could reduce neonatal mortality rates by as much as $40 \%$ in high mortality settings [3-6]. 
There are a number of reasons why our potential to reduce the burden of neonatal death is not currently realised on a large scale [7-9]. One important road block is identification of babies at risk. Over half of all babies born in sub-Saharan Africa for example are born at home [10] and the majority of communities and families have no access to scales or other means by which to identify a baby as small, at risk, and in need of extra care.

Simple anthropometric alternatives to measuring birth weight have been investigated in various settings. Six separate research studies from UK, India, Nepal and Taiwan have reported on studies to investigate newborn foot length as a screening tool for small babies, showing consistent foot length cut-offs for identifying small babies across different countries (Figure 1) [11-16]. Moreover, despite having different aims and objectives, five out of six of the studies concluded that for high risk babies born at home, measuring foot length in the community may have advantages over other methods. Unlike measuring chest circumference, for example, there is a relative lack of training required, and lack of disturbance to the infant that undressing might introduce.

Here we report on the first African study of newborn foot length to identify low birth weight and premature babies and give the sensitivity and specificity estimates, and positive and negative predictive values for different foot length cut-offs. The aim was to determine the utility of using foot length as a screening tool in home delivery settings to identify low birth weight or premature babies in need of extra care. Our goal was to define a simple operational foot length cut-off that could be used to screen babies as follows: (1) babies who have an urgent need for care because they are very low birth weight (<1500 grammes); (2) babies who would benefit from additional care in the home because they have birth weight 1500-2499 grams or gestational age $<37$ weeks; and (3) babies who have birth weight $>2499$ grams and gestation age $>36$ weeks, and thus do not need special care because they are small.

\section{Methods}

\section{Study design}

We conducted a cross-sectional study of newborn babies born in hospital, with a non random subset followed up at home on the fifth day of life. A clinical officer examined babies and measured their feet on the first day, an experienced field supervisor tracked and measured the feet of babies on the fifth day; a medical doctor supervised the work. All staff were trained together on the maternity ward for one week prior to the start of data collection, each repeating foot length, birth weight and gestational age measures and comparing findings.

\section{Study setting and participants}

The research was carried out between 13 July and 16 October 2009 within the framework of an ongoing randomised controlled trial (clinical trials identifier NCT01022788) called "Improving newborn survival in southern Tanzania" (INSIST). It is based in Lindi and Mtwara regions, a predominantly rural and poor area with high neonatal (43 per 1000 live births) and infant (76 per 1000 live births) mortality [17]. Seventy one percent of the population live within 5 kilometres of a health facility but around two-thirds of births take place at home.

During the study period, all babies born at the Mtwara Regional hospital, known as "Ligula hospital", were assessed for inclusion within 24 hours of birth and mothers asked to give informed written consent. Babies showing signs of any one of the following were excluded: severe respiratory distress, birth asphyxia, congenital deformity, birth weight $<1000$ grams or gestational age $<28$ weeks.

\section{Anthropometric data collection}

On the first day of life, each baby recruited in hospital for whom consent was given had their right foot measured from the heel to the tip of hallux (big) toe using a stiff transparent plastic metric ruler. Birth weight was measured using digital Salter scales which were

\begin{tabular}{|c|c|c|}
\hline Year: Town, Country & Participants and setting & $\begin{array}{l}\text { Recommended newborn foot length cut off for a reported } \\
\text { screening outcome* }\end{array}$ \\
\hline 1979: Manchester, UK & 123 babies born in hospital, measured between $12 \mathrm{hrs}-5$ days after birth & Foot length $<7.2 \mathrm{~cm}$ to identify babies born light for dates \\
\hline 1984:Udaipur, India & 300 babies born in hospital, measured between $24-48 \mathrm{hrs}$ of birth & Foot length $<7.2 \mathrm{~cm}$ to identify babies born birth weight $<2500 \mathrm{~g}$ \\
\hline 1988: Bombay, India & 200 babies born in hospital, measured within $48 \mathrm{hrs}$ of birth & Foot length $<6.5 \mathrm{~cm}$ to identify babies born $<34$ gestational weeks \\
\hline 1993: Pune, India & 89 babies born at home, measured within 48 hrs of birth & $\begin{array}{l}\text { Foot length }<6.3 \mathrm{~cm} \text { to identify babies born }<1500 \text { grams } \\
\text { Foot length }<7.5 \mathrm{~cm} \text { to identify babies born }<2500 \text { grams }\end{array}$ \\
\hline 2007: Sarlahi, Nepal & 1640 babies born in an intervention project, measured within $72 \mathrm{hrs}$ & Foot length $<6.9 \mathrm{~cm}$ to identify babies born $<2000$ grams \\
\hline 2009: Kaohsiung, Taiwan & 256 hospital retrospective record review from routine birth data & $\begin{array}{l}\text { Reports an association with birth weight but no foot length cut- } \\
\text { off recommendation given }\end{array}$ \\
\hline
\end{tabular}



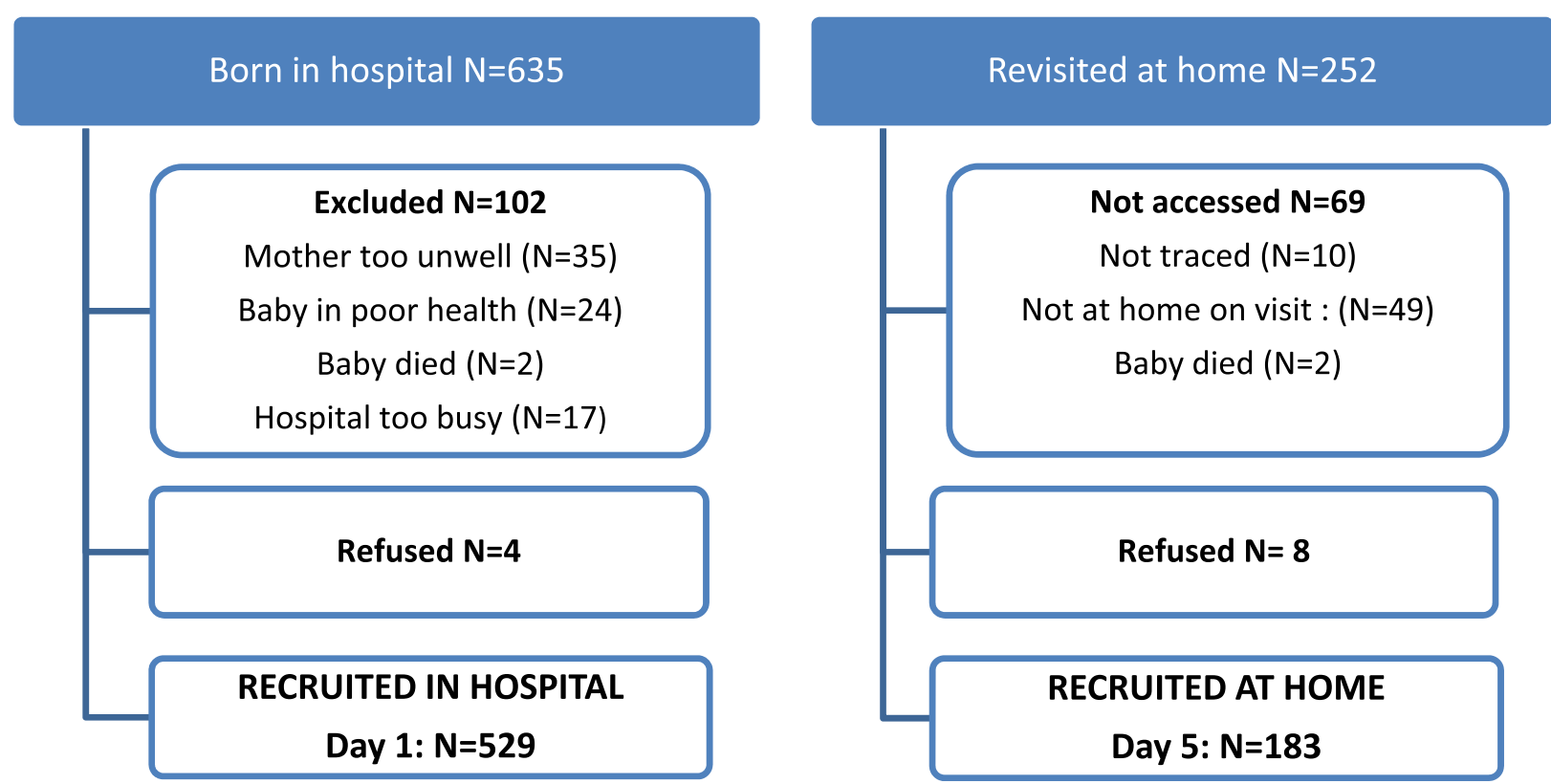

Figure 2 Newborn recruitment flow chart. Showing number of babies born in hospital during the study period who were recruited on the first day of life, and number of these babies who lived within 20 kilometres of hospital and who were visited at home on the fifth day of life.

calibrated at each use with a bottle weighing 1000 grams. Gestational age was estimated by the Eregie method [18,19] which adapts the Dubowitz score [20] for African babies; in short, 6 physical characteristics of babies were examined and scored for signs of maturity (skin, eyes/ears, breast size, genitalia, mid-upper arm circumference, and head circumference).

Mothers were asked to give their home address and those estimated to live within 20 kilometres of the hospital were asked for permission for project staff to make a home visit on the fifth day of baby's life to re-measure foot length. This was then compared to the first day newborn foot length, birth weight, and gestational age estimate to explore the association up to five days after birth. Finally, project staff were asked to comment on the ease of implementation of the foot length measurement, and to report any perceptions of acceptability by parents.

\section{Data processing and statistical analysis}

Data was entered directly into personal digital assistants at point of measurement on the first and fifth day of life, with internal consistency checks pre-programmed. Data was analysed using STATA version 10.0. The distribution of gender, birth weight, foot length and gestational age estimates for the babies measured on the first day and the fifth day subset were compared using $\mathrm{Chi}^{2}$ test for heterogeneity to look for evidence of difference between the two samples that could introduce bias. We defined three binary variables to describe outcomes: (1) less than 1500 grams (very low birth weight), (2)less than 2500 grams (low birth weight) and (3)less than 37 weeks gestation (premature). Babies with these outcomes are referred to as 'small' in this context.

The absolute difference in foot length measured on the first and the fifth day for individual babies was calculated. Non-parametric receiver operating characteristics (ROC) analysis was conducted on first and fifth day foot lengths for the three outcome variables. To generate a simple operational foot length cut-off for babies with low birth weight or prematurity, a range of foot lengths was then defined as those that approximated $80 \%$ sensitivity and $80 \%$ specificity across the three outcomes. Sensitivity, specificity, positive and negative predictive values were calculated for these foot lengths.

\section{Ethical approval}

The study was approved by the Institutional Review Board of Ifakara Health Institute, Tanzania, the Medical Research Coordinating Committee, Tanzania and the London School of Hygiene and Tropical Medicine, UK. Written, informed consent was obtained from the caregiver of each infant in the study.

\section{Results}

\section{Study population}

During the study period, 635 babies were born at Ligula Hospital of whom 529 (83\%) were recruited to the foot length project and had their feet measured on the first day of life. According to maternal reports, 257 lived 
within $20 \mathrm{~km}$ of the hospital and of these 183 (71\%) had their feet measured again on the fifth day of life (Figure 2 ). The mean birth weight was 2.9 grams (SD 0.4), and mean gestational age was 39.5 weeks (SD 2.4). The two samples were similar with respect to gender, birth weight, newborn foot length and prematurity $\left(\chi^{2} \mathrm{p}>\right.$ 0.05 , table 1$)$. Of the 529 babies, eight (2\%) were born very low birth weight $(<1500$ grams); $78(15 \%)$ were born low birth weight ( $<2500$ grams); 44 ( $8 \%$ ) were born premature $<37$ weeks. Amongst the premature babies, seven (16\%) had birth weight <1500 grams and $37(84 \%)$ had birth weight between 1500-2500 grams.

The mean foot length of the 529 babies measured on the first day of life was $7.8 \mathrm{~cm}$ (standard deviation 0.4), and the mean foot length of the 182 babies measured on the fifth day was $8.1 \mathrm{~cm}$ (SD 0.3). On average, each baby's foot was $0.2 \mathrm{~cm}$ (SD 0.3) longer on the fifth day than on the first day.

\section{Sensitivity, specificity, positive and negative predictive values of foot length}

Sensitivity and specificity estimates for different foot lengths measured on the first day to identify small babies are shown in figures 3, 4 and 5 in the form of non-parametric receiver operating characteristics (ROC) curves. Assuming an $80 \%$ cut-off for both sensitivity and specificity to be desirable, we observe that this is achieved for very low birth weight $(<1500 \mathrm{~g})$ at foot lengths $<7.2 \mathrm{~cm}$ and $<7.5 \mathrm{~cm}$ respectively (figure 3 ), for low birth weight $(<2500 \mathrm{~g})$ at foot lengths $<7.9 \mathrm{~cm}$ and $<7.6 \mathrm{~cm}$ (figure 4 ), and for prematurity ( $<37$ weeks) at foot lengths $<7.7 \mathrm{~cm}$ and $<7.5 \mathrm{~cm}$ (figure 5).

Using this range of foot length estimates as a guide, we show in table 2 the sensitivity and specificity for two simple and potentially operational foot length cut-offs: $<7.0 \mathrm{~cm}$ to identify very low birth weight babies $<1500 \mathrm{~g}$ who need urgent care and $<8.0 \mathrm{~cm}$ to identify other small babies (low birth weight $<2500$ g or gestational age $<37$ weeks).

Fourteen newborns (3\%) had a foot length $<7 \mathrm{~cm}$, and $275(52 \%)$ a foot length of $<8 \mathrm{~cm}$ on the day of birth. Of the eight babies with birth weight $<1500 \mathrm{~g}$, six had foot length $<7 \mathrm{~cm}$ and all had feet shorter than $8 \mathrm{~cm}$. Of the 77 babies with birth weight $<2500 \mathrm{~g}, 14$ had foot length $<7 \mathrm{~cm}$ and 67 had feet shorter than $8 \mathrm{~cm}$. Of the 44 premature babies, 12 had foot length $<7 \mathrm{~cm}$ and 41 had feet shorter than $8 \mathrm{~cm}$.

Newborn foot length of $<7 \mathrm{~cm}$ had sensitivity and specificity of $75 \%$ (95\% confidence interval $36-100$ ) and $99 \%$ (95\% confidence interval 97-99) respectively to identify birth weight $<1500$ grams, foot length of $8 \mathrm{~cm}$ had sensitivity and specificity of $87 \%$ (95\% confidence interval 79-94) and 60\% (95\% confidence interval 55-64) respectively to identify birth weight $<2500$ grams, and foot length of $8 \mathrm{~cm}$ had sensitivity and specificity of $93 \%$ (95\% confidence interval 82-99) and 58\% (95\% confidence interval 53-62) to identify premature babies.

On day five, foot length of $8 \mathrm{~cm}$ had sensitivity and specificity of $77 \%$ (95\% confidence interval 74-86) and $74 \%$ (95\% confidence interval 51-88) respectively to identify low birth weight babies, and foot length of $8 \mathrm{~cm}$ had sensitivity and specificity of $79 \%$ (95\% confidence interval 73-85) and 72\% (95\% confidence interval 44-98) to identify premature babies (table 2).

The positive predictive values (PPV) for these foot length cut-offs were low, being highest at $43 \%$ for the 7 $\mathrm{cm}$ cut-off to predict very low birth weight. The

Table 1 Characteristics of newborns measured on the first day only and for the sub-sample of babies also measured on the fifth day

\begin{tabular}{|c|c|c|c|c|c|c|c|}
\hline \multirow[b]{2}{*}{ Gender } & \multicolumn{2}{|c|}{ All babies $N=529$} & \multicolumn{2}{|c|}{ First day only $N=346$} & \multicolumn{2}{|c|}{ First and fifth day $N=183$} & \multirow[t]{2}{*}{$\chi^{24}$ p-value } \\
\hline & $n$ & $\%$ & $\mathrm{n}$ & $\%$ & $n$ & $\%$ & \\
\hline Male & 283 & 52 & 188 & 54 & 95 & 52 & \\
\hline Female & 246 & 48 & 158 & 46 & 88 & 48 & 0.5 \\
\hline \multicolumn{8}{|l|}{$\overline{\text { Birth weight }^{1}}$} \\
\hline Very LBW $(<1500 \mathrm{~g})$ & 8 & 2 & 7 & 2 & 1 & 0.5 & 0.1 \\
\hline LBW $(<2500 \mathrm{~g})$ & 78 & 15 & 55 & 16 & 23 & 12 & 0.2 \\
\hline \multicolumn{8}{|l|}{ Foot length ${ }^{2}$} \\
\hline Very short feet $(<7 \mathrm{~cm})$ & 14 & 3 & 12 & 3 & 2 & 1 & 0.1 \\
\hline Short feet $(<8 \mathrm{~cm})$ & 275 & 52 & 178 & 51 & 97 & 53 & 0.7 \\
\hline \multicolumn{8}{|l|}{ Gestation weeks ${ }^{3}$} \\
\hline Premature (<37 weeks) & 44 & 8 & 30 & 9 & 14 & 8 & 0.6 \\
\hline
\end{tabular}

${ }^{1}$ Birth weight measured within 24 hours using digital Salter scales. Mean birth weight for all babies was 2922 grams (95\% confidence interval $2880-2964$ ).

${ }^{2}$ Foot length measured within 24 hours of birth using a hard ruler. Mean foot length for all babies was $7.8 \mathrm{~cm}$ (95\% confidence interval $7.8-7.9$ ).

${ }^{3}$ Gestation age in weeks estimated using the Eregie method [18]..

${ }^{4} \chi^{2}$ test to look for evidence of difference between the first day only and the first and fifth day subset of newborns. 


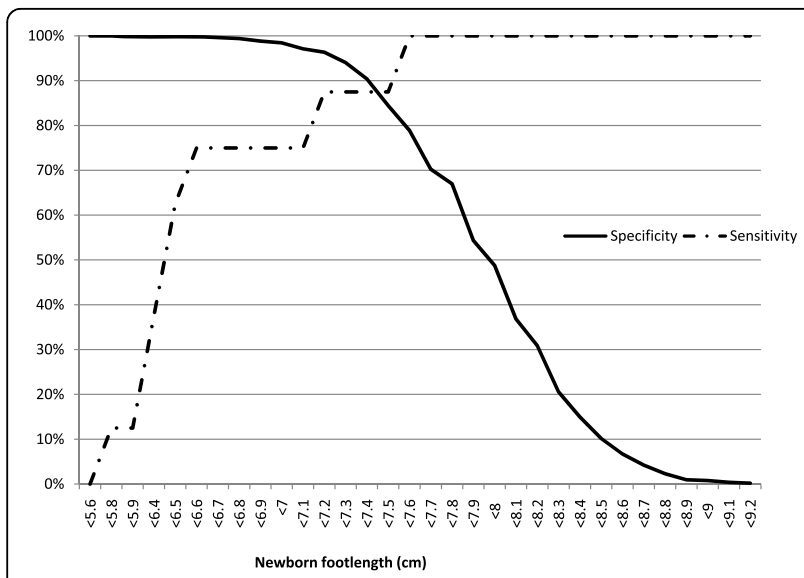

Figure 3 Sensitivity and specificity of newborn foot length to predict very low birth weight ( $<1500$ grams). Foot length measured on first day of life with a hard plastic transparent ruler.

negative predictive values (NPV) were high at $96 \%$ for low birth weight and $99 \%$ for very low birth weight (table 2).

\section{Qualitative observations}

Project staff reported that using the ruler to measure feet was simple to learn and to explain to others: overall, the approach was easily understood by parents. The exceptions were the four mothers who refused in hospital who reported a fear of association with measuring baby length for coffins, and the eight fathers who refused at the home visit because they had not been present for, or informed about, the participation in hospital on the first day.

\section{Discussion}

Measuring newborn foot length in Tanzania using a simple transparent plastic ruler can identify babies

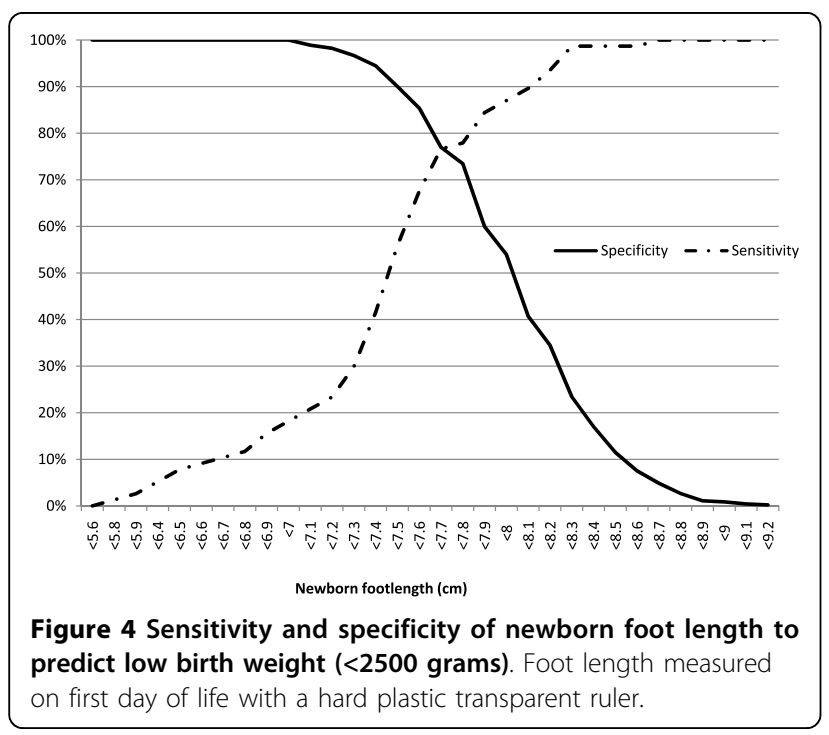

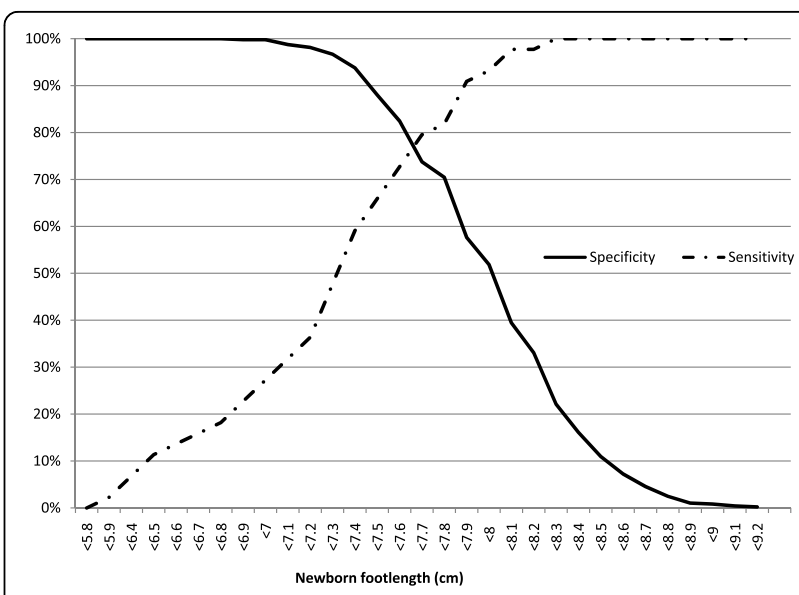

Figure 5 Sensitivity and specificity of newborn foot length to predict prematurity ( $<37$ weeks gestation). Foot length measured on first day of life with a hard plastic transparent ruler.

needing extra care because they are low birth weight or premature. A foot length of less than $7 \mathrm{~cm}$ at birth was $75 \%$ sensitive and $99 \%$ specific to identify very low birth weight babies (<1500 grams) and foot length less than $8 \mathrm{~cm}$ had sensitivity and specificity of $87 \%$ and $60 \%$ to identify those with low birth weight $(<2500$ grams), or $93 \%$ and $58 \%$ to identify those born premature $(<37$ weeks). The average newborn foot length increased by only $0.2 \mathrm{~cm}$ by the fifth day of life, and foot length measured on day five identified more than three-quarters of babies who were born small. The foot length cut-offs of 7 and $8 \mathrm{~cm}$ defined in this African setting were very similar to that previously recommended to identify small babies in Europe (7.2 $\mathrm{cm}$ ) [11], and in Asia (between $6.3 \mathrm{~cm}$ and $7.2 \mathrm{~cm}$ ) [12-15].

\section{Strengths and limitations of the study}

This was a cross sectional hospital based study of babies at birth with a community follow-up on the fifth day of life: findings suggest that measuring newborn foot length even days after birth could be useful to identify babies needing extra care. We defined 'small babies' both by birth weight and by gestational age but had a small sample size for analysis of the relatively rare occurrence of very low birth weight $(<1500 \mathrm{~g})$. Although the hospital based recruitment was not representative of the population level, the prevalence of low birth weight $(<2500 \mathrm{~g}, 15 \%)$ was consistent with previous findings [21]. Very little data exists at the population level with which to calculate prematurity rates in sub-Saharan Africa. Our estimate of $8 \%$ was lower than the $20 \%$ estimate reported previously from Malawi [22] with the implication that we may have underestimated the specificity for prematurity. 
Table 2 Sensitivity, specificity, positive and negative predictive values of short foot length to identify small baby outcomes $^{1}$ in southern Tanzania

\begin{tabular}{|c|c|c|c|c|c|}
\hline First Day of life & & Sensitivity $(95 \% \mathrm{Cl})$ & Specificity $(95 \% \mathrm{Cl})$ & Positive predictive value $\%$ & Negative predictive value $\%$ \\
\hline Foot length & Outcome & & & & \\
\hline$<7 \mathrm{~cm}$ & very LBW $(<1500 \mathrm{~g})$ & $75 \%(36-100)$ & $99 \%(97-99)$ & 43 & 99 \\
\hline$<8 \mathrm{~cm}$ & LBW $(<2500 \mathrm{~g})$ & $87 \%(79-94)$ & $60 \%(55-64)$ & 24 & 96 \\
\hline$<8 \mathrm{~cm}$ & Premature (<37 wks) & $93 \%(82-99)$ & $58 \%(53-62)$ & 15 & 99 \\
\hline \multicolumn{6}{|l|}{ Fifth Day of life ${ }^{2}$} \\
\hline Foot length & Outcome & & & & \\
\hline$<8 \mathrm{~cm}$ & LBW $(<2500 \mathrm{~g})$ & $77 \%(74-86)$ & $74 \%(51-88)$ & 29 & 96 \\
\hline$<8 \mathrm{~cm}$ & Premature (<37 wks) & $79 \%(73-85)$ & $72 \%(44-98)$ & 19 & 98 \\
\hline
\end{tabular}

${ }^{1}$ Small baby outcomes are very low birth weight $(<1500 \mathrm{~g})$, low birth weight $(<2500 \mathrm{~g})$, and premature $(<37$ weeks gestation).

${ }^{2}$ number of very low birth weight babies in fifth day subset was too small to include in analysis.

\section{Public health implications}

The utility of an anthropometric surrogate to identify small babies in the community will largely be determined by the implementing environment [14]. The Lives Saved Tool (LiST) [23] estimates that in a high mortality setting such as Tanzania, $76 \%$ of neonatal deaths could be prevented if mothers and newborns were connected to comprehensive obstetric care, neonatal resuscitation and management of encephalopathy [9]. However, the majority of newborns live in environments characterised by gaps in coverage of essential interventions, in quality of health services, and in equity [24].

In 2009, WHO and UNICEF released a joint statement promoting community volunteer programmes to make home visits to newborns as a strategy to improve survival, especially where access to facility-based skilled care is limited [25]. In Tanzania, and other African and Asian countries, there is growing political support for such programmes, but some reluctance for volunteers to carry weighing scales, because of fears about cost, maintenance, and sustainability. In these settings, the use of a simple, cheap and reliable foot length tool to screen for low birth weight or premature babies could greatly strengthen the potential health impact of community volunteer programmes.

In figure 6 we consider foot length screening in the context of a hypothetical community volunteer programme for the estimated annual 800,000 home births in Tanzania, of whom 12,000 babies could be expected to be born with very low birth weight and 120,000 with low birth weight. If volunteers used a screening cut-off of $7 \mathrm{~cm}, 20,820$ newborns would be targeted with advice about urgent medical care for very low birth weight, 9,000 of whom would be correctly targeted; 3000 very low birth weight babies would be missed. If a screening cut-off of $8 \mathrm{~cm}$ was applied, 415,560 newborns (half the home birth population) would be targeted with advice about additional care for low birth weight babies in the home, 100,920 of whom would be correctly identified. Using these cut-offs in combination, fifteen thousand 
low birth weight babies across the country would be missed, but all very low birth weight babies would be captured.

\section{Further research}

Two previous studies have reported high inter- and intra-observer agreement of foot length when measured by trained medical staff $[11,12]$. However, the reliability of foot length when measured by birth attendants, community volunteers and the mothers themselves is not yet known. We are unaware of any research or programme using foot length as a proxy for birth weight or prematurity on a large scale. This home screening tool has unknown, but promising, potential for mortality impact when integrated with home-based interventions for moderately low birth weight babies including skinto-skin care, exclusive breastfeeding, and recognition and referral of danger signs [3-6,8].

\section{Conclusions}

In resource poor settings where neonatal mortality remains disproportionately high, there are many missed opportunities to provide extra care to premature or low birth weight babies born at home. This study has shown that the simple and inexpensive measurement of newborn foot length can be used to screen for low birth weight and prematurity, with great potential for impact on newborn survival.

\section{Acknowledgements}

We are thankful to the members of staff at the maternity hospital at Ligula Hospital and to all caregivers of newborns enrolled in this study. Elibariki Mkubo, Mwajuma Chemba, and Rose Sagga collected the foot length data. The work was supported by grants from The Batchworth Trust and the Bill and Melinda Gates Foundation through Save the Children US. The funders had no role in the design and conduct of the study; in the collection, analysis and interpretation of the data; or in the preparation, review, or approval of the manuscript. This paper is published with the permission of the Director-General of NIMR, for whose support we are grateful.

\section{Author details \\ 'Department of Global Health and Development, LSHTM, 15-17 Tavistock Place, London WC1H 9SH, UK. ${ }^{2}$ Ifakara Health Institute, PO Box 78373, Plot 463, Kiko Avenue, Mikocheni, Dar es Salaam, Tanzania. ${ }^{3}$ Department of Disease Control, LSHTM, Keppel St, London WC1E 7HT, UK. ${ }^{4}$ Swiss Tropical \& Public Health Institute, Socinstrasse 57, PO Box 4002 Basel, Switzerland.}

\section{Authors' contributions}

TM and JAS were responsible for the study concept and design. Statistical analysis and interpretation was conducted by TM, JJ, SP, MT and JAS. TM wrote the first draft, TM, JAS, SP, JJ and MT revised the paper and contributed to discussion. All authors read and approved the final manuscript. TM acts as guarantor for the study.

\section{Competing interests}

The authors declare that they have no competing interests.

Received: 3 August 2010 Accepted: 19 October 2010 Published: 19 October 2010
References

1. Black RE, Cousens S, Johnson HL, Lawn JE, Rudan I, Bassani DG, Jha P, Campbell H, Walker CF, Cibulskis R: Global, regional, and national causes of child mortality in 2008: a systematic analysis. Lancet 2010, 375(9730):1969-87.

2. Lawn JE, Cousens S, Zupan J: 4 million neonatal deaths: when? Where? Why? Lancet 2005, 365(9462):891-900

3. Lawn JE, Kerber K, Enweronu-Laryea C, Massee Bateman O: Newborn survival in low resource settings-are we delivering? BJOG 2009, 116(Suppl 1):49-59.

4. Baqui AH, Ahmed S, El Arifeen S, Darmstadt GL, Rosecrans AM, Mannan I, Rahman SM, Begum N, Mahmud AB, Seraji H: Effect of timing of first postnatal care home visit on neonatal mortality in Bangladesh: a observational cohort study. BMJ 2009, 339:b2826.

5. Darmstadt GL, Bhutta ZA, Cousens S, Adam T, Walker N, de Bernis L: Evidence-based, cost-effective interventions: how many newborn babies can we save? Lancet 2005, 365(9463):977-988.

6. Lawn JE, Mwansa-Kambafwile J, Horta BL, Barros FC, Cousens S: 'Kangaroo mother care' to prevent neonatal deaths due to preterm birth complications. Int J Epidemiol 2010, 39(Suppl 1):i144-154.

7. Bhutta ZA, Darmstadt GL, Haws RA, Yakoob MY, Lawn JE: Delivering interventions to reduce the global burden of stillbirths: improving service supply and community demand. BMC Pregnancy Childbirth 2009, 9(Suppl 1):S7.

8. Darmstadt GL, Lee AC, Cousens S, Sibley L, Bhutta ZA, Donnay F, Osrin D, Bang A, Kumar $V$, Wall SN: 60 Million non-facility births: who can deliver in community settings to reduce intrapartum-related deaths? Int J Gynaecol Obstet 2009, 107(Suppl 1):S89-112.

9. Lawn JE, Kinney M, Lee AC, Chopra M, Donnay F, Paul VK, Bhutta ZA, Bateman M, Darmstadt GL: Reducing intrapartum-related deaths and disability: can the health system deliver? Int J Gynaecol Obstet 2009, 107(Suppl 1):S123-140, S140-122.

10. UNICEF: State of the World's Children 2010. New York: United Nations Children's Fund (UNICEF) 2009.

11. James DK, Dryburgh EH, Chiswick ML: Foot length-a new and potentially useful measurement in the neonate. Arch Dis Child 1979, 54(3):226-230.

12. Daga SR, Daga AS, Patole S, Kadam S, Mukadam Y: Foot length measurement from foot print for identifying a newborn at risk. J Trop Pediatr 1988, 34(1):16-19.

13. Hirve SS, Ganatra BR: Foot tape measure for identification of low birth weight newborns. Indian Pediatr 1993, 30(1):25-29.

14. Mullany LC, Darmstadt GL, Khatry SK, Leclerq SC, Tielsch JM: Relationship between the surrogate anthropometric measures, foot length and chest circumference and birth weight among newborns of Sarlahi, Nepal. Eur J Clin Nutr 2007, 61(1):40-46.

15. Mathur A, Tak SK, Kothari P: 'Foot length'-a newer approach in neonatal anthropometry. J Trop Pediatr 1984, 30(6):333-336.

16. Ho TY, Ou SF, Huang SH, Lee CN, Ger LP, Hsieh KS, Huang SM, Weng KP: Assessment of growth from foot length in Taiwanese neonates. Pediatr Neonatol 2009, 50(6):287-290.

17. Armstrong Schellenberg JR, Mrisho M, Manzi F, Shirima K, Mbuya C, Mushi AK, Ketende SC, Alonso PL, Mshinda H, Tanner M: Health and survival of young children in southern Tanzania. BMC Public Health 2008, 8:194.

18. Eregie CO: A new method for maturity determination in newborn infants. J Trop Pediatr 2000, 46(3):140-144.

19. Sunjoh F, Njamnshi AK, Tietche F, Kago I: Assessment of gestational age in the Cameroonian newborn infant: a comparison of four scoring methods. J Trop Pediatr 2004, 50(5):285-291.

20. Dubowitz LM, Dubowitz V, Goldberg C: Clinical assessment of gestational age in the newborn infant. J Pediatr 1970, 77(1):1-10.

21. UNICEF and WHO: Low Birthweight: Country, regional and global estimates. 2004 [http://whqlibdoc.who.int/publications/2004/9280638327. pdf].

22. van den Broek N, Ntonya C, Kayira E, White S, Neilson JP: Preterm birth in rural Malawi: high incidence in ultrasound-dated population. Hum Reprod 2005, 20(11):3235-3237.

23. Victora CG: LiST: using epidemiology to guide child survival policymaking and programming. Int J Epidemio/ 39(3):650-652 
24. Kinney MK, Black KJ, Cohen RE, Nkrumah B, Coovadia F, Nampala H, PM Lawn JE: Sub-Saharan Africa's Mothers, Newborns, and Children: Where and Why Do They Die? PLOS Medicine 2010, 7(6):e1000294

25. WHO and UNICEF: Home visits for the newborn child: a strategy to imporve survival: Joint statement. 2009 [http://whqlibdoc.who.int/hq/ 2009/WHO_FCH_CAH_09.02_eng.pdf].

\section{Pre-publication history}

The pre-publication history for this paper can be accessed here: http://www.biomedcentral.com/1471-2458/10/624/prepub

doi:10.1186/1471-2458-10-624

Cite this article as: Marchant et al:: Measuring newborn foot length to identify small babies in need of extra care: a cross sectional hospital based study with community follow-up in Tanzania. BMC Public Health $201010: 624$

\section{Submit your next manuscript to BioMed Central} and take full advantage of:

- Convenient online submission

- Thorough peer review

- No space constraints or color figure charges

- Immediate publication on acceptance

- Inclusion in PubMed, CAS, Scopus and Google Scholar

- Research which is freely available for redistribution

Submit your manuscript at www.biomedcentral.com/submit 